\title{
¿Democracia islámica? \\ De la primavera árabe al invierno musulmán
}

\section{Islamic democracy? From the arab spring to the muslim winter}

\begin{abstract}
Antonio Hermosa Andújar ${ }^{1}$
hermosa@us.es

\section{Resumen}

Este artículo analiza el recorrido de las conexiones entre el islam y los procesos democratizadores que se aglutinaron en tono a la "primavera árabe", originados por las multitudes en las calles. Este proceso, aún inconcluso, vislumbra un final menos feliz de lo esperado en el cual juega un rol definitorio la religión coránica, enemiga de la democracia. Frente a ello, el autor propone, en primer lugar, los rasgos que definen la democracia para luego relacionarlos con el núcleo de la tradición coránica y, finalmente, establecer cómo los movimientos religiosos han obrado en relación a los principios democráticos.
\end{abstract}

\section{Palabras claves}

Democracia, Estado, religión, principios democráticos, primavera árabe, religión coránica

\section{Abstract}

This article analyses the extend of the connections between islam and the democratization processes that came together with the "arab spring", originated by the crowds on the streets. This process, even, envisages a less happy ending than what was expected, in which Coran's religion plays a definitive role, enemy of democracy. In face of this, the author proposes, firstly, the features that define democracy to then relate them with the nucleus of Coran's tradition and, finally, establishes how religious movements have acted in relation to democratic principles.

\section{Keywords}

Democracy, State, religion, democratic principles, arab spring, Coran's religion.

Forma sugerida de citar: HERMOSAANDÚJAR, Antonio (2013). “Democracia islámica? De la primavera árabe al invierno musulmán”. En: Universitas, XI (19), julio-diciembre, p. 17-48. Quito: Editorial Abya Yala/Universidad Politécnica Salesiana.

1 Docente de la Universidad de Sevilla-España. Director de la Revista Araucanía. 


\section{Introducción}

En el mundo árabe, las sociedades islámicas han tejido una polifacética red de "resistencia y protesta" (Bennani-Chraibi y Fillieule, 2004) ${ }^{2}$ desde tiempos inmemoriales, mientras las lealtades familiares, tribales o regionales dominaron incontestablemente la zona (Hourani, 1968) o también mientras el nacionalismo autoritario dominaba la escena pública; pero hasta lo que se ha dado en llamar "primavera árabe" nunca rozaron el corazón de la democracia. Cuando se les ha querido buscar un cierto pedigrí se ha remontado especialmente hasta el Egipto del siglo XIX (o hasta los esfuerzos contemporáneos de Turquía ${ }^{3}$ y Líbano por construir puentes hacia la modernidad), cuando el Estado se ordena siguiendo el modelo organizativo francés; o bien al de las décadas de 1920 a 1950, cuando se produjo el experimento liberal que el nacionalismo árabe de Nasser y la hegemonía social y cultural de los hermanos musulmanes acabaron de enterrar.

Algunas de las sociedades aludidas conocieron momentos de esplendor laico, como el propio Egipto, Iraq o Siria, países en los que determinados movimientos sociales acaban siendo políticamente representados por un partido único que, a imitación de los Estados totalitarios fascistas o comunistas, se adueñaba de las estructura del Estado bajo un jefe que se adueñaba de las estructuras del partido, transformándose en un régimen. ${ }^{4}$ Del laicismo que les inspiraba ideológicamente mantuvieron -por un tiempo y de manera interesada- los lazos que les unían a la secularización, ${ }^{5}$ en tanto segaban de un tajo cuanto les vinculaban a la democracia.

A decir verdad, a finales del pasado siglo diversos países árabes incorporaron en su seno político ciertos rasgos claramente democráticos, como son los procesos electorales y el sistema multipartidista (opendemocracy.net). A partir

2 El libro está consagrado a la explicación de tales fenómenos sociales en el siglo XX. (Véase también Mernissi, 2003: 43-50).

3 Es la unidad cultural de los países islámicos, por lo demás no exenta de diferencias que la atraviesan geográfica, social, política, lingüística, cultural y hasta religiosamente, lo que nos lleva a veces a alinear a Turquía en el mundo árabe. (Para la diferencia entre árabes, turcos y persas véase Hourani, 2003: 119-122).

4 Lo que explica el exceso de burocratización presente en cada uno de ellos, típico de la tradición oriental, en la cual, por otro lado, el Estado es más "feroz" que fuerte. (Véase Ayubi, 1998: 580).

5 Seculares y nacionalistas, dice Zabaida, pero en todo caso no democráticas, sea que se aliasen con el constitucionalismo liberal, el fascismo o el socialismo (opendemocracy.net). 
de ahí surgieron algunos fenómenos que denotan una mayor pluralización y liberalización de las sociedades islámicas, los cuales, aun cuando no se les puede calificar de democráticos, despertaron ilusiones de que ciertos efectos suyos emprendieran ese camino. Como afirma Ayubi, algunos de esos fenómenos forman parte de lo que puede llamarse "democracia cosmética", pero nada impide que ahí se gestara de manera insospechada alguna raíz democratizadora. Un fuego que podía prender a partir de las algaradas callejeras que durante la década de los 90 sacudieron los cimientos de varios países como Marruecos, Túnez, Turquía e Irán; o bien a partir del refuerzo en la autonomía de la administración de justicia inspirado por el mayor relieve adquirido por la figura de la ley en el organigrama estatal; o bien a partir de los intereses que se concentraban en grupos definidos fuera del círculo gubernamental y de las asociaciones próximas a él; o incluso, por último, a partir de los pactos y las cartas nacionales mediante los cuales se accedía a una nueva legitimidad y estabilidad políticas o se aspiraba a una renovada reconciliación nacional (Ayubi, 1998: 596-602).

Con todo, la conexión más profunda jamás establecida entre el islam y la democracia se ha producido a través de la llamada "primavera árabe", un movimiento que probablemente adeuda su origen a las "revueltas por la comida" o las "protestas contra la austeridad" que antes incluíamos en las algaradas callejeras, y que tras su inicio en diciembre de 2010 en Túnez, se extendió como un reguero de pólvora por otros países colindantes. Lo que al principio se presentó en sociedad como una petición más de trabajo y como una demanda de mejora de las condiciones sociales de la población, pronto añadió una exigencia absolutamente revolucionaria a sus demandas habituales: la de libertad. Era la democracia lo que se buscaba junto a la introducción de cambios positivos en las condiciones laborales y los resultados, tan rápidos como inesperados, al menos por la mayoría de los negativamente afectados, pronto cambiaron la faz de diversos países de la región. La democracia se exigía al tiempo que era practicada por las multitudes en calles y plazas (opendemocracy.net); reclamó, contra la propia historia de los países musulmanes, instituciones, prácticas y procedimientos inspirados en la tradición occidental; clamó sin cesar contra sus propios gobernantes en lugar de hacerlo, al son de una cacareada ideología, contra sus enemigos naturales y, en su empuje, terminó por derribar sucesivamente a varios déspotas de sus tronos, interrumpiendo además esa cadena 
tiránica de poder que se configura tan pronto como el detentador del mismo piensa en forjar su propia dinastía, según nos enseñara Herodoto (2000: 96105) milenios atrás.

Dicho proceso no ha concluido todavía, pero ya ha experimentado cambios sustanciales que hacen prever para el mismo un final menos idealista del que se prometió. En ese final no feliz, nuestra convicción es que la religión coránica, enemiga de la democracia, ha jugado un papel esencial. Intentaremos, en el resto del trabajo, 1) fijar algunas de las características básicas de toda democracia (con independencia de que muchas de ellas no se cumplan o no en los países occidentales) y 2) relacionarlas con el núcleo de la tradición coránica, es decir, analizar cómo los movimientos religiosos que actúan en su nombre y son partidarios de su imposición al conjunto de la sociedad, han obrado hasta aquí en relación con los principios democráticos que en la actualidad dicen sustentar y practicar.

\section{Principios democráticos}

El primero de ellos, tanto histórica como normativamente, y condición de los demás, es la secularización, vale decir, la separación entre religión y política, que en su origen tardo-medieval se manifestó como separación entre la Iglesia y el Imperio ${ }^{6}$ y más tarde como separación entre la Iglesia y el Estado. El paso supone una revolución en toda regla, tanto respecto de la inmanencia de la política como para la constitución del individuo y su reconocimiento jurídico como sujeto de derechos. Es también, en cuanto hecho, el antecedente del laicismo, la cara teórica de la medalla secularizadora.

6 Acerca de dicha problemática la bibliografía es infinita, por lo que solo recordaré aquí uno de los textos más brillantes que conocemos, el de Paolo Prodi (2000). Prodi considera que esa separación es una de las señales distintivas del proceso de formación de las libertades y de su consolidación democrática en las sociedades occidentales (que completará más tarde con otro texto igualmente excepcional dedicado a las relaciones entre Estado y mercado, en el que la necesaria autonomía de uno y otro resultan decisivas para la libertad [Prodi, 2009]). De ahí su lamento en el capítulo final, ante el hecho más que manifiesto de la imposición de la ley positiva sobre la ley moral. Con todo, la pérdida de autoridad religiosa que esto último conlleva -la Iglesia es el poder principal que subyace a la validez de la norma moral- no solo nos parece un hecho positivo, sino una condición indispensable para el mantenimiento de las libertades, en especial la de conciencia, básica en la configuración de la dignidad individual. 
El laicismo, que considera el mundo humano como una realización humana y al Estado como un ente sustancialmente autónomo de la religión, considera asimismo a la religión como un ente sustancialmente autónomo del Estado y la práctica de las creencias religiosas como un derecho individual. Solo que ahora la religión ha dejado de ser la estrella que guía el rumbo de la sociedad a través de sus magos o de los híbridos a los que transustancia, como los reyes, y ha abandonado la esfera pública para encerrarse en el ámbito privado, donde continua siendo la luz de la conciencia de los fieles. Por decirlo con palabras de Marcel Gauchet: "salida de la religión no significa salida de la creencia religiosa, sino salida de un mundo al que la religión estructura, en el que ordena la forma política de las sociedades y en el que define la economía del vínculo social" (Gauchet, 1998: 13).

La idea ahí implícita es muy sencilla: es posible un Estado religioso, confesional, pero es imposible que dicho Estado sea democrático. La democracia implica secularización y laicismo para nacer y sobrevivir, y si cualquiera de los dos elementos faltara cabría sin duda la posibilidad de divisar en el escenario político la celebración de elecciones libres y a gobernantes emancipados del clero ejerciendo sus funciones, solo que no serían sino fantasmas democráticos paseando ocasionalmente por la arena pública.

Añadamos que el correlato individual de la inmanencia del Estado inherente al proceso secularizador es la libertad de conciencia. Cada sujeto profesará las creencias que elija ${ }^{7}$ tendrá derecho a su tutela estatal en iguales condiciones que las de sus correligionarios o que las de la competencia. Ahora bien, al sujeto le cabe optar no solo por la libertad de creencias, sino -como ilustrara Spinoza $-^{8}$ por la libertad de las creencias (religiosas), por liberarse del mundo de superstición que las genera y al que reproducen, así como de la infinita irracionalidad que conllevan y de la cruel violencia a que dan lugar; y ello con la seguridad de que la profesión de fe laica vale tanto como cualquier fe religiosa o de que aun siendo ateo se puede ser mejor ciudadano que el militante de cualquier religión. Cabría rubricar una seguridad más: el laicismo, potenciando

7 Podríamos, en la mayoría de los casos, decir mejor que "le elijan", pero desde el momento en que un sujeto racional las ejerce voluntariamente las está convalidando como suyas, esto es, legitimando.

8 El primero "en reducir el ateísmo en sistema", como dijo Pierre Bayle (Israel, 2002: 160; véase también Spinoza, 1986: 61-68). 
la igualdad de todos los individuos al reconocer su común humanidad, al contrario de cuanto es connatural a los miembros de cada secta religiosa, no solo no es un vaciado moral neutro, sino un ideal de justicia y emancipación que representa la sola opción ética consecuente con la mencionada igualdad.

Otro principio democrático básico es el pluralismo. En dicha forma caben diversos contenidos, pero aquí nos ceñiremos a uno solo: el reconocimiento de la irreductible singularidad individual y la legitimidad de las consiguientes diferencias y posibles conflictos en los modos de vida de cada sujeto. El pluralismo, así, completa el sistema de la igualdad desde la diferencia. ${ }^{9}$ Declarando válidas por principio las distintas cosmovisiones de los individuos, las diversas teorías del bien a que dan lugar y sus respectivas prácticas, salvo las originadas en la violencia, y legitimando al tiempo los potenciales conflictos que de ellas pudieran derivar, declara iguales a los sujetos que las sostienen. A partir de aquí ya no es posible fundar supremacías originarias, y ninguna referencia al credo, a la raza, al género, a la estirpe, a la posición social, a la riqueza, etc., bastará para cimentar ninguna autoridad ingénita de un individuo sobre otro: la naturaleza, el estatus o la religión han perdido todo poder sancionador.

Ahora bien, en tal modo el individuo no solo se libera de la dependencia del Señor o del Amo merced a la igualdad común, sino que por mor de la legitimidad de sus formas de vida, que solo el recurso a la violencia anula, se libera asimismo de la dependencia del Estado, o mejor, se convierte en un deber para él. El vínculo con el constitucionalismo, con los derechos humanos y con el mito nuclear de la democracia, la soberanía popular, queda en este punto fijado con solidez; mas también con el liberalismo en el aspecto, esencial, que revela la esencia del pluralismo como un límite al ejercicio del poder del Estado, dimensión esta que, por ejemplo, el pluralismo social, al constituir la sociedad en grupos de intereses y naturalizar su presencia en la misma más allá de la voluntad estatal -es decir, al concebir la vida social y política como un sistema poliárquico, contrario por naturaleza al absolutismo político- no hará sino apuntalar. Añadamos que el pluralismo se acompaña además de una epistemología

9 Jocelyn Maclure y Charles Taylor (2011: cap. 1) muestran con evidencias la continuidad existente entre libertad de conciencia y pluralismo moral. 
escéptica y de una ética relativista, ${ }^{10}$ que en conexión con la doctrina jurídica de los derechos humanos genera una teoría social centrada desde y punto de vista axiológico sobre el individuo en lugar de sobre la comunidad; sobre un ser cuya conciencia tasa los valores que adopta para regir gran parte de su vida y cargado de derechos y obligaciones en relación con los demás y con el Estado. El predominio de la comunidad sobre sus integrantes, los valores adscriptivos, de matriz trascendente o no, y el absolutismo político quedan abolidos por tanto de un plumazo, o bien el egotismo individualista de quien ignora la necesidad, con sus correspondientes leyes, de la existencia del otro junto a él.

El tercer rasgo, en conexión sistémica, que no histórica, con el anterior es la soberanía popular. La igualdad de todos los ciudadanos implica transferir a la mayoría aquello de lo que se privó a uno o a la inmensa minoría: la condición de ciudadanos que los lleva de inmediato ante las puertas de la soberanía asentándolos definitivamente en el trono del poder social. Del que en lo sucesivo ya no se les desalojará sino mediante el uso de la violencia, una mancha que cuando cae sobre la arena pública transforma el escenario en un erial porque nunca desaparece, dado que, como expresarán de manera áurea Maquiavelo primero y luego Kant - en contextos, por razones y con fines diversos- el recuerdo de la libertad no se cancela de la memoria de los ciudadanos. Hoy, ningún tirano es ya legítimo, por mucho consenso social que le sostenga (y ello a pesar del creciente descrédito que puebla el mundo democrático). Y, desde luego, ha transcurrido ya una eternidad desde que se viera a Dios llevando de la mano al Rey o una cordillera de privilegios separar al noble de sus criados. Incluso el dinero ha dejado de privilegiar, como lo hacía incluso en los primeros regímenes liberales, a sus nuevas deidades frente a quienes sufren la renovada prepotencia. Todo ello es lógicamente inherente a la proclamación del pueblo como sujeto político único y al reconocimiento del conjunto de sus miembros en cuanto iguales.

Ese tercer rasgo se mezcla en las democracias contemporáneas con los principios liberales del constitucionalismo y del Estado de Derecho, y absorbe asimismo el ímpetu revolucionario consagrado en los Derechos del Hombre y

10 Por paradójico que pudiera parecer, es esa ética relativista la que ha conferido respetabilidad a toda esa caterva de creencias absolutistas que, de imponerse alguna, convertiría la vida de quienes no la profesaran en tierra quemada, vale decir, en algo quizá peor, caso de ser posible, de lo que ya ha devenido la mente de sus acólitos (laicismo.org). 
del Ciudadano en Francia y en la segunda enmienda a la Constitución de los Estados Unidos -bien que, en realidad, una notable parte de razón asistiera al federalista Hamilton cuando se resistía a su Declaración constitucional al verlos ya puestos en práctica en la división de poderes y en la ordenación federal del territorio. Porque, ciertamente, el efecto común de tales elementos es la división y limitación de los poderes del Estado, así como el control de su ejercicio mediante el principio de legalidad; lo cual se suma a la consagración del sujeto individual reconociéndolo libre además de igual, e incluso a un elemento clave en el nuevo sistema de justicia establecido: la eliminación de la violencia del ámbito de la justicia. Idea ésa cuyo desarrollo exige un proceso de formalización y objetivación que, entre otros muchos resultados, abarque a todos los ciudadanos y no solo a los héroes, y tase a todos con la misma regla; que separe el daño de su réplica por la otra parte y considere la entidad del mismo como medida de la sanción, según sostiene la bíblica y no bíblica Ley del Talión; o, en fin, que despolitice el castigo desligándolo del arbitrio del gobernante.

El cuarto y último rasgo lo constituye el primado de la política. Una vez producido el desencantamiento del mundo, con las fuerzas naturales desterradas de la racionalidad y los saberes, fundados en su inmanencia, estructurados de acuerdo con su lógica interna, la política debe cumplir su función única en la sociedad: garantizar su seguridad y su paz, primero, y fomentar la libertad y el bienestar después. Los enemigos son, en potencia, las demás, aunque en acto acuerdos y tratados pueden desactivar ese bélico potencial. Mas lo son también las sociedades mismas, por cuanto sus miembros, arrastrados por pulsiones insolidarias, no raramente malinterpretan o reniegan de los vínculos de solidaridad con los que el individualismo, que concibe al sujeto como un ser social por naturaleza, los entrelaza. Además, los grandes grupos de interés, auto-legitimados para devenir grupos de presión, fuerzan con frecuencia las reglas a fin de arrimar el ascua a la sardina cada cual del suyo a costa del de los otros si es necesario.

En este sentido la política, que desde su resurgimiento en el mundo moderno había soltado su lastre religioso y marcaba su territorio frente al mercado, ve cómo poco a poco, a través del liberalismo primero y de la democracia luego, se le añaden, en cuanto saber, una teoría que explica su naturaleza y refuerza su autonomía, y como práctica el mundo de la libertad y de los derechos junto a la garantía de la Constitución, al objeto de preservar a ambos y que proteja la 
unidad y coordinación de su poder sin sufrir los efectos de su fuerza; que medie entre los conflictos que todos esos elementos, juntos o por separado, producen por su misma naturaleza sin verse destruida por ellos. Fines esos a los que la realidad colorea a menudo con el tinte heroico de los ideales.

En aras de la satisfacción de su función tutelar de la sociedad y la libertad individual, la democracia por tanto protege a la política de los demonios de la religión y de la tiranía del mercado: de fiar su ejercicio a los burócratas divinos por medio de los cuales el dios de turno impera en la sociedad y de que el mercado, merced a las diversas potencias surgidas del culto a la suprema deidad del dinero, la conforme a su imagen y semejanza construyendo una sociedad de mercado habitada por lobos en permanente acecho de su interés egoísta. La consecuencia más determinante de ese proceso de afirmación de la política democrática es la construcción social del futuro, una tarea siempre inacabada a la que el escultor debe intentar modelar extrayendo sucesivamente formas del mármol del tiempo, en función de las circunstancias, de su voluntad y de su poder; siempre en conexión con otros actores del entorno, cada vez más planetario, y siempre con la libertad y la paz como telos. Ideas, técnica, negociaciones, pactos continuarán proveyendo de los medios más frecuentes con los que llevarla a cabo, y conforman junto a esa sombra de azar que rodea todo lo humano los ingredientes fundamentales de la acción con la que la sociedad se abre paso entre la maleza de posibilidades para elegir la suya. Un último ingrediente facilitará su eficacia: que la acción que construye la arquitectura del futuro se vea cada vez más adelgazada en su obrar del peso del pasado.

Hemos sintetizado en cuatro los rasgos que, en principio, definen a una democracia. Si ahora dirigiésemos la mirada a cualquier democracia real, incluidas las de mayor pedigrí histórico o sociológico, a fin de medir su alcance y calibrar su pleno rendimiento en los hechos, advertiríamos sin sorpresa que posiblemente ninguna reproduce cabalmente el modelo, vale decir, comprobaríamos una vez más la a veces sideral distancia, y aun contradictoria, que separa la teoría de su práctica. Si viajáramos, por ejemplo, al Reino Unido oiríamos a su actual primer ministro afirmar que Inglaterra es cristiana, al tiempo que leemos los resultados de una encuesta que rebajan el número de los que así se declaran, entre otras razones a causa del aumento notable de quienes se profesan ateos (laicismo.org); en todo caso, lo que nunca hallaríamos es una 
completa secularización, y ni tan siquiera una estable libertad de culto, pues de ser así no nos saldría al paso la reina en persona predicando la protección de la misma (laicismo.org).

Ahora bien, a pesar de las insufribles carencias en la materia, no hay democracia occidental que en mayor o menor grado no respete los cuatro rasgos expuestos en su funcionamiento cotidiano; y aun cuando al escéptico cabrá siempre recurrir a los casos de Italia o España, entre otros, para afirmar sus dudas respecto de la separación entre la Iglesia y el Estado en ambos países; o al de la entera región sureña de la Unión Europea - por no hablar de los propios Estados Unidos y del contubernio que allí se produce de continuo entre política y empresa- para rebatir la autonomía del Estado frente al mercado, una tesis que a día de hoy suena con razón sarcástica en numerosos oídos de diversos lugares, cabría igualmente recordarle que también existen los países nórdicos, cuyos sistemas democráticos disiparían sin tardar buena parte de sus remilgos.

\section{El islam y la democracia}

Ni uno solo de los principios referidos es propiedad del islam. Es mucho más sencillo y certero afirmar que predica lo opuesto. Y, por ende, arribar por la vía de urgencia a una conclusión que alguien calificará de precipitada $-\mathrm{y}$ a su autor, quizá, de orientalista extraviado- esto es, que son lisa y llanamente incompatibles. ¿Significa eso también que los pueblos hundidos en el islam son naturalmente ajenos a la democracia? Las dos cosas, frente a toda apariencia, distan de conformar una, así que vayamos por partes.

El corazón del islam se halla segmentado por diversas cesuras que constituyen otras tantas barreras insuperables para su democratización: la que escinde al hombre de la mujer; al creyente del infiel (sea este ateo o creyente de una fe falsa); al islámico del apóstata. En los tres casos, no solo se sanciona la supremacía del primer miembro de la relación sobre el segundo, sino que a veces el ultraje al segundo se acompaña de su muerte: la igualdad, la secularización o la libertad de conciencia o de culto que la democracia hiciera sangre de su sangre son aquí extirpadas de raíz. Incluso la paz misma ve peligrar su seguridad. De 
los derechos fundamentales, en su conjunto, ha desaparecido todo rastro antes siquiera de aparecer en escena.

La discriminación en el mundo intraislámico, iniciada en el último par señalado, prosigue entre el piadoso y el que no lo es, así como entre chiís y sunís, que pone de nuevo sello religioso a esta ampliación de la desigualdad. Que se ensancha con otra cesura imborrable entre el mundo islámico y su endogamia normativa frente al otro, y que ahora, además, sí pone a la paz en verdadero peligro al convocar a la guerra como posible solución del conflicto: la existente entre "dar al-islam" y "dar al-kbar", el mundo de los infieles, despreciable por naturaleza en cuanto no islámico, y al que los creyentes deben conquistar por las buenas, mediante el proselitismo resuelto en conversión, o por las malas: por medio de las armas, los soldados de Alá deben imponer su credo por la fuerza cuando el ardor argumentativo del fanatismo falla.

Un dios que está en el origen de todo y es fin de todo cuanto hagan sus esclavos, que eso quiere decir precisamente islam, ${ }^{11}$ preside sus vidas mediante un conjunto de prescripciones y prácticas preestablecidas de antemano, de valor absoluto y validez intemporal. La administración del futuro, así, se ha deshumanizado para siempre, al igual que la libertad en su dimensión ontológica y la carga de incertidumbre que introduce en las cosas humanas, que como sabía Kant -y mucho antes Epicuro- constituye la prueba viva de su existencia. Y como la "verdad"12 no se discute ni renueva, no se negocia ni matiza, la razón solo está en el esclavo creyente para no errar en su fe y la voluntad para obedecer. El pluralismo, que se siente y sabe agnóstico y relativista por naturaleza, sería un pecado en medio de esa lógica si algún resquicio le hubiera dado cabida en la misma.

Asimismo, el califa y el imán, que suelen ser dos personas pero pueden ser la misma, y entre los chí́s lo es (Hattstein, 1997: 110 en Cisneros, 2004: 137), junta la función religiosa del funcionario sagrado con la mundana del fun-

11 Para Vercellin (2002: 5-6), el término "islam" expresa una "concreta y activa sumisión a la voluntad del Dios único". No cabe la menor duda de que se trata de un gran honor, aunque involuntario, que en la lengua árabe, la del Corán, se designe a Occidente con el término garib, que "es también el lugar de las tinieblas y de lo incomprensible [algo que] es siempre espantoso" (Mernissi, 3002: 23).

12 Este es uno de los rasgos del mundo árabe, junto al matrimonio política-religión, que a decir de Felipe Mansilla (s/f.), conforman el legado árabe a las sociedades latinoamericanas vía "colonización ibérica". 
cionario político, suprimiendo en esta dimensión de la vida del creyente toda diferencia entre lo público y lo privado, al estar la espada subordinada a la fe y sentarse esta en lo más alto del trono. ${ }^{13}$ La mera posibilidad de secularización, de laicismo, incluso de división y control del poder, ha quedado pues abortada de antemano: la República Teocrática de Irán está para demostrarlo. ${ }^{14}$

El conjunto de creencias y prácticas antidemocráticas y liberticidas recién resumidas pone de relieve hasta qué punto resultaría peligroso para la humanidad atender a las peticiones de numerosas autoridades religioso-políticas islámicas que, ante las críticas a su inefable profeta, solicitaron a la ONU el establecimiento del delito de blasfemia a escala internacional (elmercuriodigital.net). Las creencias son por lo general irracionales, y las religiosas lo son de modo absoluto, por lo que la única salvaguarda ante ellas es mantener la libertad de pensamiento y de crítica como bien jurídico universal, en cuanto son las principales barreras intelectuales y éticas en grado de preservarnos del mundo de barbarie al que aquéllas potencialmente dan lugar; e incluso de la destrucción mutua, y total, que ocasionarían si circularan a su aire sin más en una misma sociedad, de no ser porque el relativismo democrático, asentado jurídicamente en los derechos humanos, las protege de sus efectos al tiempo que nos protege a los demás.

Un ejemplo de lo que, merced a dicha tutela, son por ahora solo contradicciones a nivel teórico lo constituye la reclamación de los musulmanes en los países democráticos con sociedades abiertas y multiculturales, basándose precisamente en el derecho a la libertad religiosa -que implica "la libertad de adhesión a creencias religiosas", así como "la de manifestar la filiación religiosa mediante el culto, los ritos y la difusión de la fe" (Maclure y Taylor, 2011: 87)-, del reconocimiento de su religión, y en concreto de declarar vigente la Sharía

13 Recuérdese que el asesino del entonces primer mandatario egipcio, Anuar el-Sadat, coronó su magnicidio gritando "he matado al faraón", y el motivo, compartido por todo el islamismo y justificado por él, era simplemente que Sadat "había colocado la ley humana por encima de los preceptos religiosos" (Rogan: 620).

14 Palabras de su primer imán, el ayatolá Jomeini: "en esta democracia [...] las leyes no se hacen por la voluntad del pueblo, sino solo según el Alcorán y la tradición del profeta”. Y para subrayar aún más al cielo como poder legislativo: "la sagrada legislación del islamismo es el único poder legislativo. Nadie tiene el derecho a legislar y no puede ejecutarse ninguna ley como no sea la ley de la divina legislación" (Gellner, 1989: 147). 
entre ellos, sin importar los conflictos que su aplicación desataría con determinados derechos humanos... incluido el de la libertad religiosa misma: y es que, y aquí subyace la contradicción, al mismo tiempo se niega dicha libertad, o se concede un restringido uso de la misma, a las demás confesiones religiosas en el mundo musulmán, donde aquélla impera. En cuanto "creyentes deben comprender que su libertad solo estará garantizada si defienden la libertad de otros con quienes se hallan en profundo desacuerdo" (Scheffer en Schammah y Rein, 2011: 53). Un deber ése que ya hemos visto sobradamente cómo los "creyentes" musulmanes y sus autoridades lo comprenden.

No obstante, en apariencia hay una respuesta fácil, un hecho clave que refutaría nuestra tesis de que islam y democracia son enemigos natos el uno de la otra y al contrario. Esa respuesta es el hecho de que Turquía es un país islámico con un Estado democrático. En efecto, la inmensa mayoría de la población turca profesa la religión islámica, mas la democracia, se dice, se encuentra asentada con firmeza entre ella. Nos topamos aquí con una paradoja: no hay democracia en Occidente que responda en la práctica a sus principios, en tanto en Oriente Medio damos con una democracia en un país islámico, que rebate la esencia del islam. En Turquía, las elecciones que renuevan la clase política son limpias y regulares, la división de poderes está fijada en la constitución y la ciudadanía se halla investida del derecho a ejercer libremente la crítica, profesar el culto de su elección, reunirse y, en suma, adoptar el modo de vida que le plazca. Turquía, en suma, es el crisol que funde dos mundos teóricamente incompatibles. ¿Cómo es posible?

Aceptamos, pero no sin rechistar, el carácter democrático del antiguo enfermo de Europa, como reconocemos que el déficit democrático de su Estado, enorme, debe muy poco al islam y mucho a su historia reciente, la iniciada con la fundación de la actual república turca por Mustafá Kemal Atatürk, si bien la deuda aumenta en el presente. El conflicto externo de Turquía con kurdos y, especialmente, armenios o su vocación de hegemonía regional no son criaturas sorpresa accidentalmente derivadas de las sucesivas victorias electorales del Partido de la Justicia y el Desarrollo y de su líder, Recep T. Erdogan. Como tampoco los conflictos internos entre los diversos poderes estatales o entre el Ejército y el Poder Ejecutivo, más intermitente este que aquél hasta casi ayer, lo son; bien que hoy día tales conflictos ya no se planteen en su crudeza tradi- 
cional debido a la autoritaria solución que, mediante la fuerza, ha conseguido aplicar el primer ministro Erdogan. Con todo, pese a tales desvaríos antidemocráticos legados por la historia a la política turca, así como por las tentaciones autoritarias de las que es presa continua el actual primer ministro turco (auroraisrael.co), cuyo reflejo se advierte incluso en la postergación de la fecha de acuerdo de la Comisión Constitucional, fijada para el 31 de diciembre de 2012 (hurriyetdailynews.com), Turquía parece haber unificado dos realidades que nosotros consideramos antitéticas: democracia e islam. ¿Es esto así?

Pensamos que no. En Turquía hay democracia y hay islam, pero lo que no hay es una democracia islámica, al igual que tampoco hay en Occidente una democracia cristiana -a pesar de la pléyade de partidos políticos creados bajo semejante paraguas ideológico con el objeto de confundir religión y políticael espantapájaros teórico que sirvió de musa al partido gobernante turco. En lugar de una (im)posible democracia islámica, una democracia inspirada en principios coránicos o islamistas en general, la yuxtaposición de ambas cosmovisiones es la realidad dominante en Turquía. Más aún: ni el origen ni la organización del Estado turco derivan directa o indirectamente de preceptos extraídos del Corán o de cualquier otra fuente normativa islámica, ni la conducta de gobernantes y ciudadanos se halla regida por la Sharía, algunos de cuyos castigos -los de los delitos de tipo hadd, por ejemplo, para los que se prescriben penas particularmente severas- han sido proscritos del código penal turco. Con otras palabras: la medida en la que Turquía es democrática marca la distancia que la separa del islam; solo porque no es por entero islámica puede ser democrática, y solo porque no es por entero democrática puede ser islámica, aunque en la conducta de los individuos quepan fusiones ocasionales entre ambas. Pero cada vez que el Parlamento turco adopta normas en pro del islamismo está añadiendo una muesca más a la culata de su revólver antidemocrático (decisiones ésas que no son privativas del mismo, sino que por desgracia se hallan demasiado extendidas en los países democráticos).

Ahora bien, ¿significa eso, como planteábamos anteriormente, que a todo país islámico le está vedada la democratización? Si, en verdad, siguiendo el rastro de ilustres estudiosos occidentales del islamismo, como Bernard Lewis o Ernest Gellner (Lewis, 2003; Gellner, 1996), nos empeñáramos en sostener una idea semejante, habríamos abandonado el terreno de la historia para entrar 
en el de la naturaleza. Porque una cosa es que el islam sea inconciliable con la democracia y otra bien distinta, aunque relacionada, es que un país que profesa mayoritariamente la religión islámica no pueda cambiar de fe. Desde luego, si nuestra tesis es cierta, precisamente el hecho de querer democracia es síntoma de que ya la ha perdido, o para expresarnos sin metáforas: un país consecuentemente islámico, cuyos individuos practicasen con el debido celo el islamismo -aparte de que se habría vuelto loco o, simplemente, se habría autodestruido entre la maraña de contradicciones que lo acoquinan- nunca querría aquello que más lo refuta; no desearía vivir bajo un régimen que lo niega públicamente, pues lo relega a sistema de creencias privado, igual desde un punto de vista axiológico en esa esfera a los demás, y ajeno por completo, como todos, a la arena pública.

La historia registra en sus anales la necesidad del cambio, y en ello no admite excepción alguna: tampoco para los países árabes y otros pueblos vecinos que profesan la religión de Mahoma, como es el caso de turcos e iraníes. La primavera árabe, convertida por los partidos confesionales en auténtico invierno musulmán, nos da fe de ello, pese a los decepcionantes resultados hasta ahora obtenidos por las revoluciones que la hicieron florecer. El lector nos permitirá que demos una larga cita de lo que escribíamos al principio de la misma, ligeramente retocado.

Primero fue Túnez; luego vinieron Argelia, Egipto, Jordania, Yemen y otra vez Túnez. En fin, la calle árabe de nuevo está que arde, mas esta vez el incendio carece del aire festivo que tuvo cuando fueron derribadas las torres gemelas, o de la rabia divina que desató en la conciencia musulmana, sea la publicación de las caricaturas del Profeta en el diario danés Jyllands-Posten, sea el puntual dardo malévolo que periódicamente suele lanzarle el jefe de la competencia católica; ni proviene de cualquier otro hecho puntual suscitado por el maligno occidental, que nunca descansa. Pero tampoco, y esto sí que es grave, de la-descontada-madre de todas las protestas, el único foco permanente de gangrena, un verdadero descuido de Alá, quien debió de andar distraído ese día porque si no, por muy británicos que sean los británicos, no se la habrían colado. O sea: del conflicto palestino-israelí.

Imagino al multiculturalista de turno - un nombre adecuado para calificar en occidente a un miembro reflejo de las élites árabes- yendo algo perplejo 
tras las causas del incendio. ¿Y con qué se topa? Pues, simplemente, con un sujeto inesperado: una multitud que crece y se renueva a sí misma conforme va cambiando su grito, que pasa de ser una dolorida consigna contra el subdesarrollo y el autoritarismo, esto es, contra el hambre, la pobreza, el desempleo, la desigualdad y la corrupción, a convertirse en un enardecido programa de reivindicación política en el que la marea crece desde la petición de dimisión de ciertas autoridades a la exigencia de un cambio de régimen. Multitud sin duda enloquecida, pensará nuestro tolerante multiculturalista, porque, a ver, ¿qué hace una mayoría de árabes islámicos reclamando reformas políticas que, de ponerse en práctica, llevarían incluso a confundirles con los sistemas políticos del enemigo? Y, por si fuera poco, todo eso como si nada. Total, llega uno, se quema a lo bonzo, ique mira que es poco musulmán eso!, además, y la chispa que ahí salta quema el palacio. ¡Ni que fuera esta la primera vez en su historia que pasan hambre o están sometidos, ni que no fuera ésa su forma de ser! ¡Aquí hay gato encerrado!, clamará para sus adentros, mientras rumia ya cómo desmontar el complot.

$\mathrm{Y}$ es que, en efecto, una parte de lo que había ocurrido, y otra cada vez mayor de cuanto ocurría, no estaba escrito en el guión de la historia local, salvo como nota a pie de página a lo sumo, ni tampoco en las suras coránicas. Pase que una sociedad partida en dos por varios costados vea rebelarse a la parte mayoritaria demandando una cura para sus urgencias: mejores salarios contra el hambre, empleos que ilusionen con un horizonte a su futuro, incluso algo más de justicia que diluya un tanto la ignominia en las desigualdades creadas por los privilegios, etc.; pase asimismo que esa rebelión tome cuerpo tras un hecho tan irrespetuoso como es que a alguien le dé por inmolarse, en sí un ejercicio de vanidad que no tiene en cuenta la tradición religiosa de llevarse por medio a algún enemigo del islam, pero que en esta ocasión ha llevado, en su soberbia, hasta a organizar, aunque sea algo informalmente, la rabia y sacarla a pasear en público, en contra de la tan probada tradición política; pase, faltaría más, que sobre los rebeldes las fuerzas del orden ejerzan su violencia habitual, pues por qué dejarles hacer lo que quieren, tan en contra de lo que deben.

Ahora bien, lo que no puede pasar es que una vez empiezan a disiparse las brumas de los primeros enfrentamientos entre ambos bandos -esto es, la estela de muerte, de sangre, de dolor, de miedo y de rabia renovada que el choque 
de la violencia contra los rebeldes produjo en sus filas, incitándoles a la respuesta-, el mayoritario, el de los enragés, comience asimismo a vislumbrar los rasgos del que, con mayor o menor razón, consideraba entonces responsable último de la situación, que le ponga el nombre y el rostro de su presidente, y el de sus allegados, y a la petición de pan sume la exigencia de libertad. O sea: lo que no debía pasar, según las cuentas de cuantos consideran la reclamación de libertad una muestra más del imperialista ideario occidental, es que una multitud que salta a la calle con una determinada idea en la cabeza, por no decir en el estómago, mute mientras la recorre y llegue a la plaza convertida en dueña del palacio: en un nuevo sujeto político que, primero, reclama diversas libertades, para acto seguido atribuirse la soberanía y ejercerla de inmediato, forzando la deposición de los miembros afines al anterior autócrata presentes en el Gobierno recién formado tras su huída. Pues sí, lo que les quedaba por ver: ¡una antigua masa árabe informe que ha embocado por el momento su transformación en pueblo soberano a la occidental!

Tal fue a grandes trazos el cuadro de lo sucedido en Túnez, el patrón en cierto sentido de cuanto vino después, incluidos los acontecimientos egipcios, pese a la importancia considerablemente mayor de estos por ser Egipto el país que es. Pero ya se sabe que a los imitadores no les gusta la virginidad de la historia: como, recibido el empujón -éxito oblige- suelen tener prisa por abandonar el Ancien Règime, mejor optan por quemar etapas antes que por seguir la pauta del modelo original en toda su pureza, y en lugar de imitar los pasos uno a uno les va más lo de empezar donde terminaron los pioneros: reclamando el cambio del gobernante a la par que el del régimen, y si se acuerdan hasta reclaman también pan y trabajo. Se trata pues de un acto que, como se ve, implica un juicio completo, condena incluida, al sistema anterior. Por eso, al "dictadorsaurio" yemení, que pensaba que por haber refundado el país este sería suyo para siempre, ya no le bastará para retener lo suyo con regalar los alimentos o introducir la meritocracia en el país; y por eso, a Mubarak terminó por truncársele el deseo de instaurar en Egipto la dinastía antes de que le sucediera su primer heredero.

No ha de olvidarse que las exigencias de las plazas árabes eran de libertad. Ciertamente, en ese estado de cosas, en absoluto cabía descartar que el antiguo régimen reaccionase con éxito en busca de su termidor, sobre todo en Egipto, donde Mubarak sí reinaba sobre el ejército. Pero era mucho más fácil 
pensar que la mecha prendida inicialmente en Irán contra el robo en las urnas del triunfo de la oposición por parte del Gobierno actual siga generando más incendios. Como también lo era que cuando lo que prende la mecha es la libertad, todo lo que la refrena, antes o después, correrá peligro si no rejuvenece. Y entre ese todo figura, y de manera solemne, el propio islam. Ya en Egipto, los organizadores de las manifestaciones aceptaron la posterior incorporación de los hermanos musulmanes a condición de que renunciaran a su lema sacrosanto de que "el islam es la solución", un lema ahistórico y autoritario además de falso y cobarde. Y en Túnez, aunque aquí la historia cuenta, las fuerzas laicas prevalecieron desde el inicio.

Pero por otro lado, si algo aprendieron de inmediato los manifestantes es que la libertad de manifestación y expresión que entonces exigían estaba siendo un hecho con su protesta aun antes de que el cambio acabe por transformarla en derecho; que son ellos los que la están conquistando mientras la ejercen; y que el éxito del ejercicio exige la garantía de que podrá repetirse en el futuro cuando se juzgue oportuno. Con la misma celeridad han aprendido que en el nuevo régimen ellos deben ser el soberano. Y que ambas cosas van o pueden ir juntas...

A partir de ahí el camino es tan fácil de imaginar cómo difícil de recorrer, máxime cuando para la tradición cultural imperante representa una novedad absoluta. Pero las novedades no asustan a quienes exigen libertad mientras la ejercen, que pronto podrán aprender con Tocqueville que el precio de los males de la libertad es más libertad. Lo que es cierto es que si las revoluciones hubieran prosperado todo se habría cuestionado, incluido el papel a jugar por la propia religión musulmana en el futuro. De ser así, estaríamos en los comienzos de un proceso extraordinariamente complejo y duradero del que en absoluto podía verse ni preverse el final; pero la calle árabe llegó a sentir ese calor que esparce "l'alta crémor/del foc de llibertat" (Salvador Espríu), y también por eso desde entonces ya sabemos que entre las posibilidades aquí abiertas por los pueblos árabes a sí mismos se incluye la de que el propio islam empiece a experimentar en sus carnes su renacimiento y su ilustración, algo imprescindible si quiere convivir con la democracia en Occidente, entre otras razones.

La primavera árabe hizo nacer la flor de la democracia en aquel mundo, por lo general hostil a la misma, casi por generación espontánea, pero en cuanto brotó no tardaron en percibirse los vínculos que la engarzaban con otros epi- 
sodios del pasado. Vale la pena recordar aquí, en efecto, que a lo largo de su historia se ha citado en varias ocasiones con el laicismo, algunas de ellas desde el nacionalismo autoritario. En los siglos IX y X, por ejemplo, un conjunto de librepensadores, entre los que descuella Abu Bakr al-Razi, había resuelto la dicotomía fe/razón elevando a la última a los altares, mientras confinaban la primera en los arrabales de la proteica debilidad humana. Un pensamiento humanista y ateo desterraba la sumisión a dios y a cualquier otra autoridad fundada en él, emplazando en el corazón del paraíso a un sujeto individual en grado de distinguir racionalmente lo bueno de lo malo, lo necesario de lo inútil, una capacidad al alcance de todos los individuos, que venían así a ser declarados iguales (guardian.co). ${ }^{15}$

Oriente Próximo vivió en los siglos XIX y XX un largo periodo de reformas, que invadieron los ámbitos de la cultura, la política y los modos de vida. La nahda, el "renacimiento cultural" árabe, fructífero sobre todo en Líbano y Egipto, si bien afectó al conjunto de los pueblos árabes; supuso en pleno dominio otomano la reivindicación de "las glorias de su pasado preotomano", y constituyó prevalentemente desde la literatura la primera gran cita moderna de las sociedades islámicas con el laicismo, aun cuando sus efectos se harían sentir igualmente en el ámbito político (Rogan: 12-13, 217ss.).

La formación de los primeros Estados árabes, con Egipto a la cabeza, siguiendo el modelo básicamente francés; la aparición de los partidos políticos de corte moderno, el surgimiento de ideologías provenientes asimismo de Europa, como el nacionalismo, el liberalismo, el fascismo, el socialismo o el panarabismo constituyeron otras tantas reformas políticas que se fueron sucediendo en tierras musulmanas, primero durante el imperio otomano y más tarde bajo el paraguas del Estado nacional. Si a ellas añadimos los grandes cambios habidos en los modos de vida; en la forma de vestir; en las relaciones de género, donde

15 Hourani (2003: 107-111) cita a un falasifa, esto es, a un filósofo, Al-Farabí, entre los grandes intelectuales que preservaron la unidad de esas dos instancias separadas y contradictorias que son razón y fe; tarea llevada a cabo en un modo que precede al tantas veces socorrido en la Europa moderna, esto es, destinando el ejercicio de la razón a los filósofos y dejando la Sharía para las mentes menos dotadas (las de "ignorantes" y "extraviados", al decir del propio Al-Farabí [1985: cap. 34]). Spinoza y Locke son dos de los grandes nombres que aparecen en la aludida tradición y comparten con el autor islámico también la prevalencia del conocimiento "apodíctico" del filósofo sobre cualquier otra forma de conocer (1985: 110). 
prevalecía la igualdad entre hombre y mujer; en los hábitos de ocio de la juventud, que llevaron al extraordinario desarrollo del cine, la televisión y la música, y en los que el alcohol tenía cabida con naturalidad, percibiremos cuán hondo caló la occidentalización en tales pagos, y en cuántas direcciones se propagó el laicismo en las sociedades islámicas. Como dice Rogan (622): "dada la destacada presencia que tiene en la actualidad el islam en la vida pública de la mayor parte del mundo árabe, resulta fácil olvidar que en el año 1981 el Oriente próximo era notablemente laico". Las sucesivas crisis por las que fue pasando el mundo árabe comportaron la irrupción en escena de las fuerzas religiosas, que al prevalecer finalmente en la misma se esforzaron por borrar hasta la menor huella occidental, confundida ahora con el mal y, por ende, anatematizada como pecado.

La breve reseña histórica acerca de las vicisitudes de la irreligiosidad en el mundo islámico destaca dicha secularización como el elemento compartido entre liberalismo, nacionalismo y su actual y alicaída primavera, aparte de las vivencias de libertad así mismo comunes entre aquél y esta. Pero hoy como ayer la visión democrática del futuro de la zona divisada desde ambas perspectivas socio-políticas ha sido disipada por la intervención de los hermanos musulmanes en Egipto. Durante la crisis de la dictadura totalitaria, y pese a la represión sufrida junto a las fuerzas de izquierda, supieron sobreponerse al poder oficial gracias a su control de las mezquitas y de las instituciones de caridad, las bases a partir de las cuales suministraban a una población cada vez más necesitada los bienes materiales, servicios y trabajos que requerían, y que antaño habían constituido la contrapartida ofrecida por Nasser, quien había añadido un programa de reformas de la tierra, a cambio de una obediencia absoluta. Así empezó su dominio sobre la sociedad mientras se hallaban alejados de la política, un hecho favorecido al comenzar a gravitar en la zona de influencia de Estados Unidos en lugar de continuar en la de la antigua Unión Soviética; Sadat y Mubarak recibirían un pingüe apoyo militar y económico por parte del renovado amo a cambio de abrir las fronteras de su cerrado sistema económico al capital y a la privatización económica, los nuevos ídolos que, por su parte, inducirían más cambios en los sistemas social y político: la radical separación de las clases ${ }^{16}$ y

16 La división en ricos y pobres se acentúa con el crecimiento de la riqueza especialmente petrolera, que riega las arcas de los potentados al tiempo que acentúa la proliferación de pobres (Hourani, 1968: 521-525). 
una corrupción galopante -el personalismo y autoritarismo preservaron cómodamente su estatus.

En el Egipto actual, la reciente aprobación de la nueva Constitución demuestra que la primavera democrática se ha ido y todos saben cómo ha sido. El tiempo político camina al revés del atmosférico porque el nuevo dueño del poder ha permitido la construcción de una fachada democrática en contrapunto a la devolución del trono legal a la Sharía. Este nuevo sujeto, que se sumó tardíamente al movimiento revolucionario que exigía reformas sociales, laborales y políticas al antiguo Gobierno, que exigía la transformación democrática del régimen, concordaba con este en algunos de sus reclamos, pero temía perder su posición de privilegio en la sociedad si los deseos aireados se hacían realidad y con ellos las reformas mentales que les son inherentes.

El eslogan "el islam es la solución” volvió a surgir como grito de guerra entre sus huestes y en las sucesivas elecciones, incluidas las presidenciales, celebradas tras la renuncia de Mubarak, demostraron su arraigada implantación social. Fue el inicio de la inicua reislamización de la sociedad, anunciada primero en gestos inequívocos, como la aparición -algo prohibido en época de Mubarak- de una periodista en televisión con el hiyab (elmercuriodigital.net); consolidada después con medidas políticas de clara significación simbólica y ratificada ahora con la aprobación de una Constitución que, como antes señaláramos, impone la Sharía como demiurgo jurídico y social (laicismo.org). O por decirlo de otro modo: que la democracia, con sus libertades específicas como las de pensamiento, prensa, culto y creencias, tendrá que volver a emigrar a la región de los sueños, el lugar donde dos años atrás fuera invocada con singular apremio desde el simbólico corazón revolucionario, la plaza Tahrir de la capital egipcia. ${ }^{17}$

Con todo, el pujante sujeto que como salido de la nada ocupó durante meses el centro de los focos públicos clamando justicia social y libertad no se ha volatilizado, sino que permanece por el momento ansioso y agazapado detrás

17 Que haya sido una plaza en lugar de una mezquita el centro de la revuelta contra el autoritarismo político y social egipcio constituye en sí mismo un hecho pleno de simbolismo, y permite hacerse una cabal idea de la magnitud del cambio que el nuevo sujeto social y político trae consigo. La mezquita, en efecto, es el lugar desde donde, tanto históricamente -asesinato de los Omeyas por los Abasíes- como en la actualidad -Siria es el mejor ejemplo actual, pero también Irán- han partido las revueltas en el mundo musulmán. (Véase Cattedra y Janati en Bennani-Chraïbi y Fillieule, 2004: 132). 
de la desorientación que ha supuesto para él la inexperiencia política, ciertos desgarros internos, el aplastamiento del número y la consiguiente toma del poder por sus enemigos políticos religiosos; pero sus ideales permanecen vivos e íntegros, y su fuerza de arrastre, aunque mermada, casi total. Difícil será que el Egipto musulmán pueda caminar hacia sus añejos objetivos de manera sencilla, creyendo que la victoria del número legitima cualquier acción, y que la mayoría otorgada por el creyente musulmán a sus diversos representantes es razón suficiente para legalizar toda política. Si la Constitución quiere enmarcar la democracia en el estrecho círculo de la Sharía no ha hecho sino incubar en su seno el huevo de la serpiente, y una estela de disturbios civiles cada vez más violentos puede ser el juez que dirima el conflicto entre los partidarios de tales enemigos inconciliables. Si no deseaba dar alas a la conflictividad política, el constituyente debería haber eliminado toda referencia democrática y haber sancionado la Sharía sin más. Solo que en tal caso habría desplazado el conflicto al centro de la sociedad, porque la democracia se ha convertido en Egipto, merced a los revolucionarios de la primera hora, en mucho más que una simple formalidad, un pasatiempo contra el aburrimiento o una exposición de gestos cara a la galería occidental. La tradición, merced a su ímpetu, y pese a su mayor arraigo social, tiene de qué preocuparse ante lo nuevo.

La primavera árabe parece haber sido sepultada con los últimos acontecimientos. ¿Significa eso que la democracia está vedada a los países islámicos? Unas creencias absolutistas como las que integran la Sharía y unas prácticas autoritarias como las del islamismo político allá donde alcanza el poder, ¿autorizan a confirmar la desesperanza de un cambio democrático en la región gobernada por tales creencias y prácticas? Afirmar eso es compartir los delirios del pensamiento esencialista o de las ideologías absolutistas, reluctantes a la evidencia ontológica de que tiempo significa cambio. Si el lema "el islam es la solución" es ahistórico y falso, se debe a que se niega a aceptar que la historia narra las transformaciones naturalmente producidas por los hombres en el mundo de las cosas, que es también el suyo. Si, además, es también autoritario se debe precisamente a su afán por querer congelar una determinada forma de entender a un ser cuya naturaleza es mutar, vale decir, querer congelar una forma de ser que ya fue. Si, por último, es cobarde, la razón es que rehúye el 
reconocimiento de que el propio islam es historia, que él mismo ya cambió también y debe cambiar más.

Las razones de la esperanza frente a la desesperación de la experiencia manan de cierta pluralidad de fuentes, que van desde la ontológica de la historia humana como locus del cambio hasta el propio ejercicio del poder por los islamistas, pasando por la aparición del sujeto democrático antevisto en las sociedades islámicas, el caso turco o incluso la división religiosa del islamismo, que ocasionalmente ha llevado a las fuerzas que lo profesan a adoptar posiciones encontradas en la arena política.

Acabamos de aludir a la primera fuente. La historia surgió en occidente en las palabras de Herodoto (2000) al objeto de conservar la memoria de las gestas humanas -tanto griegas como "bárbaras"- que procuraban gloria, pero no solo por su valor de exempla, como fijaría más tarde la historiografía romana con Salustio a la cabeza, sino justamente para evitar su plena desaparición; se trataba de una empresa en clara rebeldía contra la ley del tiempo, cuya prescripción de olvido amenazaba con dejar al futuro sin pasado, o mejor, con anular la continuidad del acontecer humano y por lo tanto con la eliminación de uno y otro. Los hechos encuadrados en la categoría del Ubi sunt?, que entre la melancolía y el proselitismo dan cuenta de la fugacidad de las creaciones del hombre; o, para el presente, la volatilización de imperios inmóviles y pétreos según toda apariencia, destinados a sobrevivir contra natura, como el de la antigua Unión Soviética, y lo que más pronto que tarde veremos suceder en el confucionismo comunista de la nueva China antigua cuando la suma de procesos en marcha cristalice (Faure en Golden, 2004: 206-212), vuelven a ilustrarnos sobre la ceguera de quienes pretenden detener el tiempo simplemente porque hablen en nombre de valores intemporales... inexistentes antes de su temporal creación por los hombres.

Esto es así incluso con las instituciones religiosas, establecidas para hablar en nombre de un señor que gracias a ellas no solo existe sino que además se le entiende. Y ello pese a ser invisible y mudo. ¿Quién, por ejemplo, en tiempos de los talibanes católicos, cuando se habían infiltrado por todas las capas del tejido social manejándolo a su cínico antojo, cuando armando a su capo con un concepto intelectualmente terrorista como el de plenitudo potestatis jaleaban su autoproclamación como dueño y señor del mundo, habría podido imaginar 
que a semejante arrobamiento del poder, a semejante delirio del arbitrio habría seguido con el tiempo el surgimiento de una sociedad democrática? Cierto, sus pulsiones la llevan a salirse de dicho marco una y otra vez; de hecho, alguna sociedad occidental debe su déficit democrático al consentimiento de sus excesos más que a ninguna otra cosa, porque además de ceder territorio y soberanía al Vaticano en virtud de la firma de algún humillante Concordato; de violar incesantemente la regla de la igualdad constitucionalmente fijada, de imponer su cosmovisión a través de políticos sin principios, dicha sumisión a la Iglesia le sirve asimismo de coartada para usar el poder público en beneficio propio en esferas no directamente ligadas al interés eclesial. Con todo, los señores de ayer hoy lo son solo a ratos y por materias, y cuando a dios se le ocurre revelarse a la sociedad, y lo hace desde el santuario del mercado, ese acto de divina impiedad para con sus burócratas es al tiempo una confesión de impotencia de los mismos. Su cambio de estatus lo ha sido también de su poder.

El sujeto democrático, formado espontáneamente en la crisálida del islam es en sí mismo un huevo de serpiente incubado por este, aunque por otro lado ha sido el primer factor en desligar su nombre del terror. Ahora bien, su estructura, su funcionamiento y su empeño en exigir reformas sociales y democracia, trabajo y libertad -bienes desde luego perfectamente compatibles entre sí aunque no conformando necesariamente una unidad sistemática- constituyen otros tantos vectores contra la autoridad del islam, por lo que de proseguir su desarrollo significaría que se habría agrietado el muro totalitario con el que pretende aislar su supuesta pureza del curso de la vida: del tiempo. Ese sujeto no entraña la renuncia a las creencias religiosas por parte de quienes participan en él, pero sí una organización distinta de la profesión de fe que las centraliza, y que a partir de ahora debería coexistir en son de paz e igualdad con las de la competencia, y desaparecer todas de la esfera pública, so pena de hacer estallar ahí sus diferencias, de hacerla estallar en consecuencia, y de transformar el escenario público en una batalla sin cuartel, quizá en una guerra civil. Laicismo con su cohorte de paz social o perpetuación de la dictadura religiosa totalitaria: tal es el ser o no ser democrático de las sociedades donde domina el islamismo.

Turquía es el ejemplo tanto de que una sociedad democrática puede empezar a forjarse políticamente en tierras islámicas como de que el islam no se piensa dejar seducir por la democracia. Por el momento guardan un piadoso 
equilibrio ligeramente escorado en los últimos tiempos a favor del islamismo, que parece ir dando tirones al cuerpo político a través del sentimiento religioso de sus líderes, eco de las intenciones dominantes entre la población. Pero, hasta el momento, que una sociedad tan abrumadoramente islámica y con un partido confesional en el poder durante tres legislaturas no se haya decantado de una vez por todas por la religión tiene algo de doblemente milagroso, dado que rebaja el poder de Alá.

La pervivencia del espíritu laico infundido por el fundador de la Turquía moderna, ahora que se tambalea el poder de las instituciones en las cuales encarnó, quizá sea herencia de la época kemalista, pero es asimismo obra de un orden democrático que enseñó a la ciudadanía que las diferencias de credo, fines, intereses u opiniones entre sus miembros no eran la ocasión para desgarrarse entre sí; un logro valioso también porque el laicismo de la joven república fue desde su inicio el adjetivo de un sustantivo nacionalista de vitola netamente autoritaria.

La evolución de Turquía constituirá siendo clave para el resurgimiento y consolidación de la democracia en tierras islámicas, porque el originario papel de modelo se ha diluido notablemente ante las ínfulas sultánicas de su actual primer ministro y, sobre todo, por la incapacidad de llegar a pactos con su pasado, revelado en un ejercicio violento e impune del poder en el que han fundido sus esencias autoritarias dos enemigos antes inconciliables, el ejército y el partido gobernante, y que ha producido más víctimas recientes entre kurdos y armenios que añadir a los genocidios del pasado. Empero, ese legado de la historia turca a la política turca es ajeno al problema de la democratización de los regímenes islámicos como tales, bien que la compasiva relación de su fuente con cualquier forma de autoritarismo en tierras mahometanas favorezca soluciones como las aludidas. Pero si, a pesar de todo, la Sharía no deviene la sola fuente normativa del derecho turco, y si el poder religioso no se funde, como cabe prever, con el político, la vía turca constituirá sin duda una posibilidad a tener en cuenta en la exploración de los nuevos caminos hacia un porvenir democrático para los países musulmanes que aspiren a alcanzarlo. Y ello aun contando con los devaneos confesionales de sus actuales líderes y con las taras todavía políticamente irresolubles provenientes de su historia reciente. 
La división del islam constituye en sí misma un hecho sumamente valioso para su evolución, por cuanto un bloque monolítico, cerrado a cal y canto por sus dogmas frente a la libertad, resulta un enemigo mucho más difícil de batir que otro con las fuerzas unidas pero en discordia; y en determinadas circunstancias podría devenir una de las palancas mediante las cuales decantar dicha evolución del lado de la democracia. La división interna del islam no es solo histórico-teológica, entre chiís y sunís, sino también política, entre los diversos regímenes políticos que las encarnan o entre las diversas ramas del islam político, como las representadas por el islam moderado y el proclive al fanatismo y al terror; una tercera y decisiva división es la geográfica, y más aún que la resultante de la existencia de diversos Estados árabes o musulmanes, la que separa al islam europeo del afro-asiático: a la colonia religiosa europea de sus respectivas metrópolis de origen.

A nuestro entender, la evolución del islam, incluido el fanático y/o terrorista, depende de su fuerza, y esta se halla ante todo vinculada a su relación con el poder en el interior de una sociedad; desde luego, mucho más que a su representación de la ortodoxia. Por ello dejaremos este aspecto aquí y lo trataremos en el punto siguiente, el del ejercicio del poder político por el islamismo. En cuanto a la incidencia democrática del islam europeo, hemos de reconocer que en los últimos tiempos ha ido dando paulatinamente pruebas de una mayor sensibilidad hacia el régimen político de los países de acogida; y si bien ha seguido proporcionando asesinos y carnaza al fanatismo, hemos de recordar asimismo que sus reacciones a determinados fenómenos, que en otros momentos había sido la de sus hermanos de sangre ideológica africanos y orientales, como las habidas tras la publicación de la segunda tanda de las caricaturas de Mahoma o la prohibición en la republicana Francia del velo para ir a la escuela pública, fueron en gran medida pacíficas y civilizadas, a pesar del desacuerdo esgrimido con ambos hechos.

Una mayor integración de este islam "colonial" en las sociedades europeas, factible si se les va concediendo la ciudadanía y se les va integrando institucionalmente, lo que debe venir acompañado por su parte de pruebas de su mayor acomodo al régimen democrático -la aceptación de las normas de la escuela 
pública, el mayor respeto a la mujer, ${ }^{18}$ la lealtad al mismo, etc.- con el consiguiente abandono de las prácticas de discriminación o segregación que han dominado la conciencia europea en su relación con él, favorecerían una mayor adhesión a la democracia en suelo europeo y el reclamo de su ejemplo en tierras metropolitanas.

El contacto directo y cotidiano con una cultura laica, más crítica y participativa que la suya, en la que el individuo es el máximo responsable de las decisiones concretas que conciernen a su vida, pese a las fuertes restricciones que las condiciones laborales están introduciendo en su modus vivendi, sitúa al islam ante el dilema de la elección entre dos órdenes de valores contrapuestos. Si los europeos no fracasamos en nuestra tarea y en nuestra obligación de ampliar las circunstancias de integración, el mundo islámico deberá por fuerza renunciar a la coartada multiculturalista, que, primero, les impulsa a exigir en sus países de acogida lo que no reconocen en sus países de origen; segundo, a abdicar de la idea de integrar ambos mundos, por cuanto, y en tercer lugar, habrán de asimilar que no todo vale: que la cosmovisión islámica ha infligido una herida de muerte en el costado de la humanidad de la que esta no sanará si su enemigo no se reforma lo suficiente como para dejar de ser él en numerosos aspectos esenciales de su identidad histórica. El laicismo y las libertades ya le tienen marcado a fuego una serie de pasos irrenunciable en su evolución.

El ejercicio del poder por parte de los islamistas ofrece varias derivas posibles: desde refinar las tiranías, como en Irán, a crear una institucionalidad democrática, como en Turquía, pasando por la relegitimación teológica de regímenes autocráticos de origen laico, como Siria o Libia, o por la desvirtuación autoritaria de sistemas que se querían democráticos, como Túnez o Egipto y, en cierto sentido, Marruecos. Lo más probable es que dicho ejercicio se salde reforzando el poder absoluto intrínsecamente vinculado al islam, o que tire hacia él de las instituciones democráticas a través de las prácticas de sus élites gubernamentales, como en la excepción turca. Mas resulta igualmente factible que al ejercer el poder político el islamismo termine por embocar la senda occidental

18 Recordemos la posición secundaria desempeñada por la mujer en la cultura islámica, de la que -un ejemplo-derivan prohibiciones como la de contraer matrimonio con un hombre no islámico, lo cual, por cierto, constituye uno de los baluartes de la fe islámica, imposible de casar con los derechos humanos (Cisneros, 2004: 148). 
de la democratización. Y ello tanto en la esfera interna como en la internacional, aunque quizá antes desde la última.

La política, en efecto, debe resolver problemas, incluidos los derivados de su gestión. Y si bien la historia recarga la agenda, muchos de ellos son nuevos, para los que el pasado brinda quizá una pauta pero no aporta modelos ni soluciones definitivas. Su solución requiere de virtudes estrictamente políticas y no religiosas -aunque luego se busque y encuentre algún hilo de conexión entre unas y otras con las que justificar la autoridad-como lo prudencia, a la que la analogía, la intuición, la inteligencia, bien nutridas de lógica y de sentido histórico, convierten en el instrumento virtuoso con el cual juzgar los hechos, sopesar la situación, valorarla según las reglas adecuadas del ordenamiento legal, emitir la decisión considerada oportuna y ejecutarla sin tardar. A veces, incluso, cuando hay rumor de sables al fondo o ante catástrofes intempestivas, sin la posibilidad o sin el tiempo de acudir a las normas jurídicas, por principio la base de toda respuesta.

Si en el momento de la decisión la voluntad se sabe cuestionable en su autoridad porque hay otras fuerzas constituidas en grado de criticarla o sustituirla; si la presión exterior contribuye a moldearla y los derechos humanos llegan a formar parte del contenido de la presión; si la paz, un valor que nadie monopoliza en el concierto internacional, ni siquiera las democracias, conforma un interés para el país; si en el interior del propio movimiento islamista que está en el poder -sea por el uso de las nuevas tecnologías; por el diálogo con otras fuerzas políticas o sociales; por las enseñanzas de la experiencia; por reconocimiento, con su mea culpa correspondiente, de su comportamiento errático y de que el poder por el poder produce las incoherencias.

La política internacional, por su parte, a pesar de su sempiterna servidumbre ante la fuerza constituye un contexto poco favorable a la subsistencia de los lazos de parentesco y tribales característicos de gran parte del mundo islámico; y tampoco lo es para las relaciones de clan que han venido a sustituirlos. Por no ser, ni siquiera lo es para los vínculos supranacionales, de carácter religioso, que teóricamente conforman la unidad cultural del mundo islámico. Los Estados que ahí se desenvuelven al servicio de sus intereses, en efecto, dejan sin efecto práctico a la cacareada Umma, la comunidad religiosa en la que supuestamente cristaliza la citada unidad cultural. 
Un buen ejemplo de todo esto lo proporciona el actual contencioso sirio; por primera vez desde su constitución la Liga Árabe, en la que por razones raciales no participan otros países confesional o privadamente islámicos, como Irán o Turquía -enemigos entre sí, por cierto- sirve para otra cosa que para amenazar retóricamente a Israel y demás Occidente o para vegetar. Nunca hasta ahora habían decretado sanciones contra un país miembro, y menos por motivos de opresión política y de inhumanidad respecto de su pueblo; y aun cuando no hayan autorizado la intervención armada en un conflicto interno, ello se debe más al temor al armamento sirio, que posee armas químicas en sus arsenales, a la internacionalización del conflicto, que habría supuesto la entrada en escena de Irán, el protector del régimen Siria; y a las medidas que países liberticidas como Rusia o China podrían tomar. Con todo, el desarrollo de dicho conflicto ha puesto en evidencia no solo la fragmentación del universo religioso y político musulmán, sino la armonización de las órbitas de algunas de estas partes con las de Estados Unidos y Occidente en general, en contra precisamente del hermano árabe y musulmán, y de sus aliados -árabes o no- musulmanes.

Naturalmente, no se ha percibido aquí ninguna inflexión democrática en los países miembros de la Liga, y nada hace prever que se vaya a producir. Pero ello no obsta para que quepa pensar que los intereses de algunos de estos Estados, y como tales individuos, se satisfagan mejor democráticamente que de otro modo, y que si eso aconteciera con el viento de las circunstancias soplando a su favor una mutación tal llegue a tener lugar. Por lo demás, hay otros ejemplos de la especificidad de la política internacional en la producción de cambios políticos incluso en el mundo árabe, pero no de que alguno de ellos se oriente hacia la democracia. Empero, la mayor secularización que entrañan y la completa conciencia que proporcionan de que las decisiones políticas relativas a los mismos en absoluto arraigan en el islam religioso - las alusiones a este son una señal de su distanciamiento en lugar de una prueba de su conexión- y abren la vía a expectativas en pro de un cambio de sentido.

Para acabar, islam y democracia son incompatibles. Pero en las sociedades islámicas está el llegar a ella, porque el destino no está escrito ni en los genes ni en la historia. Es verdad que el totalitarismo religioso es el más difícil de erradicar dado que la estupidez humana no tiene cura (y que en el caso del islam posee un fuerte pedigrí); pero ya ha sido suavizado en numerosas ocasiones 
hasta hacerlo devenir la parafernalia de la hipocresía, a la que es menester sumar la existencia real de unos cuántos fieles y la meramente nominal de muchos más, en los países antes sumisos al cristianismo. La vida humana también fluye en territorio islámico, y no solo cuando tanto los que aspiran a modernizar su religión, tanto reformistas como creyentes pacíficos, se remontan a la gran tradición que les respalda, bien que la Sharía y otras manifestaciones y prácticas de totalitarismo se desvivan por acabar con ella. Su sueño es sembrar la tierra de cadáveres que en sus obras obedezcan como esclavos los cinco pilares del islam, en radical negación de lo postulado por el racionalismo laico y libertario. Empero, el cambio no entiende de geografías ni de leyes, y es por naturaleza ateo frente a toda trascendencia o divinidad que la sostenga; por ello, la historia, la política, la razón se guardan ases que un día favorable podrían ser la baza que imprima al juego del destino un sesgo apenas perceptible hoy, pero que quizá llegue a ser común mañana. La democracia está atada a uno de los cabos de ese juego, pero el nuevo príncipe que la quiere existe ya, y sabe que sus palabras y sus actos, su revolución, ha puesto en marcha su tiempo. Es su existencia la que da más sentido y esperanza a los otros factores enumerados: lo que vuelve pensable que en una tierra secularmente yerma para la libertad sea posible el cambio que la vea protagonista de la vida social; como será su comportamiento de sujeto democrático el más sólido argumento en pro de la ampliación y consolidación del régimen político que la requiere y tutela: la democracia.

\section{Bibliografía}

Al-Farabí

1985 La ciudad ideal. Madrid: Tecnos.

Al-Yabri, M. A.

2001 Crítica de la razón árabe. Barcelona: Icaria. Ayubi, N. N.

1998 Politica y sociedad en Oriente próximo. Barcelona: Bellaterra.

Bennani-Chraibi, M. y Fillieule, O. (eds.)

2004 Resistencia y protesta en las sociedades musulmanas. Barcelona: Bellaterra. 
Cisneros, I. H.

2004 Formas modernas de la intolerancia. De la discriminación al genocidio. México: Océano.

Gauchet, M.

1998 La réligion dans la démocratie. París: Gallimard.

Gellner, E.

1989 Cultura, identidad y política. El nacionalismo y los nuevos cambios sociales. Barcelona: Gedisa.

Gellner, E.

1996 Condiciones de la libertad. La sociedad civil y sus rivales. Barcelona: Paidós.

Golden, S. (ed.)

2004 Multilateralismo versus unilateralismo en Asia: el peso internacional de los “valores asiáticos”. Barcelona: CIDOB.

Herodoto

2000 Historias. Tomo I. Madrid: Gredos.

Hourani, A.

1968 "Ottoman Reforms and the Politics of Notables". En: Polks, W. R. y Chambers, R. L. (eds.), Beginnings of Modernization in the Middle East. Chicago.

Hourani, A.

2003 La historia de los árabes. Barcelona: Vergara.

Israel, J. I.

2002 The Rise of Philosophical Radicaslim. Oxford: Oxford University Press.

Lewis, B.

2003 What Went Wrong? Western Impact and Middle Eastern Response. London: Orion Books.

Maclure, J. y Taylor, Ch.

2011 Laicidad y libertad de conciencia. Madrid: Alianza.

Mansilla, F. H.

s/f Fundamentalismo islámico, modernidad imitativa y autoritarismo convencional. Manuscrito inédito.

Mernissi, F.

2003 El miedo a la modernidad. islam y democracia. Madrid: Ediciones del Oriente y del Mediterráneo.

Peñas, F. J.

2003 Hermanos y enemigos. Liberalismo y relaciones internacionales. Madrid: UAM. 
Prodi, P.

2000 Una storia della giustizia. Bologna: Il Mulino.

Prodi, P.

2009 Settimo non rubare. Bologna: Il Mulino.

Schammah Gesser, S. y Rein, R (coords.)

2011 El otro en la España contemporánea. Prácticas, discursos y representaciones. Sevilla: Tres Culturas.

Spinoza, B.

1986 Tratado teológico-político. Madrid: Alianza.

Vercellin, G.

2002 Istituzioni del mondo musulmano. Torino: Einaudi.

Viano

2006 Laici in ginocchio. Roma: Laterza.

\section{Referencias electrónicas}

http://abonnes.lemonde.fr/cgi-bin/ACHATS/ARCHIVES/archives.cgi?ID=db63d6d8c 5b2ee82316f3a4062f8f0ebbff09c70f07d621e

http://blog.zeit.de/schueler/2011/03/22/arabische-revolutionen/

http://sociedad.elpais.com/sociedad/2013/01/06/actualidad/1357489536_823122.html

http://www.aurora-israel.co.il/articulos/israel/Opinion/40409/

http://www.elmercuriodigital.net/2012/09/egipto-velado.html

http://www.elmercuriodigital.net/2012/09/el-islam-cabalga-de-nuevo.html

http://www.guardian.co.uk/commentisfree/belief/2010/may/10/islam-freedom-expression

http://www.guardian.co.uk/commentisfree/belief/2010/may/10/islam-freedom-expression http://www.hurriyetdailynews.com/constitution-commission-faces-critical-daysahead.aspx? pageID $=238 \& n I D=38165 \&$ NewsCatID $=338$

http://www.laicismo.org/detalle.php?pk=12842

http://www.laicismo.org/detalle.php?pk=18627

http://www.laicismo.org/detalle.php?pk=18635

http://www.laicismo.org/detalle.php?pk=18713

http://www.opendemocracy.net/mehmet-dosemeci/democracy-in-revolution-mediterranean-moment

http://www.opendemocracy.net/sami-zubaida/arab-spring-in-historical-perspective

Envío 20 de mayo/2013 - Aceptación 17 de diciembre/2013 